CVIA

REVIEW ARTICLE

pISSN 2508-707X / elSSN 2508-7088 https://doi.org/10.22468/cvia.2017.00094 CVIA 2017;1 (4):231-239

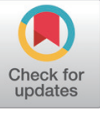

Received: July 9, 2017

Revised: September 1, 2017

Accepted: September 6, 2017

Corresponding author

Yeon Joo Jeong, MD, PhD

Department of Radiology,

Pusan National University Hospital,

Pusan National University

School of Medicine and

Medical Research Institute,

179 Gudeok-ro, Seo-gu,

Busan 49241, Korea

Tel: 82-51-240-7354

Fax: 82-51-244-7534

E-mail: lunar9052@hanmail.net

\section{Non-Coronary Findings on Cardiac Computed Tomography in Adults: What Radiologists Should Know}

\author{
Ji Won Lee', Geewon Lee', Jinhee Ahn², \\ Ki Seok $\mathrm{Choo}^{3}$, Yeon Joo Jeong ${ }^{1}$ \\ ${ }^{1}$ Departments of Radiology, ${ }^{2}$ Internal Medicine, Pusan National University Hospital, \\ Pusan National University School of Medicine and Medical Research Institute, Busan, Korea \\ ${ }^{3}$ Department of Radiology, Pusan National University Yangsan Hospital, Pusan National University \\ School of Medicine and Medical Research Institute, Yangsan, Korea
}

Cardiac computed tomography (CT) is useful for the assessment of both non-coronary cardiac disease and coronary artery disease. Various non-coronary applications are recommended in the guidelines for cardiac CT published by the American College of Cardiology. In this article, we review the non-coronary applications of cardiac CT and demonstrate typical CT case findings in adults.

Key words Multidetector computed tomography $\cdot$ Heart $\cdot$ Thrombosis · Adult.

\section{INTRODUCTION}

Recent advances in technology have made cardiac computed tomography (CT) a useful tool for detection of coronary artery disease. Several studies using 64-slice CT demonstrated high sensitivity (96-99\%) and a negative predictive value (93-99\%) of cardiac CT in excluding significant coronary artery disease [1-3]. Therefore, cardiac CT can act as a gatekeeper to invasive coronary angiography. In addition, the appropriateness criteria for cardiac CT published by the American College of Cardiology list various non-coronary applications [4]. These include evaluation of 1) complex congenital heart disease, 2) cardiac masses, 3) pericardial conditions, 4) pulmonary vein anatomy prior to invasive radiofrequency ablation (RFA) in atrial fibrillation, 5) noninvasive coronary vein mapping prior to placement of a biventricular pacemaker, 6) suspected aortic dissection or thoracic aortic aneurysm, and 7) suspected pulmonary embolism. In this article, we will review the non-coronary application of cardiac CT and demonstrate typical CT case findings in adults. Because non-electrocardiogram (ECG)-gated CT is usually sufficient to assess a thoracic aortic aneurysm or pulmonary embolism, we excluded these conditions in this pictorial essay.

(c) This is an Open Access article distributed under the terms of the Creative Commons Attribution Non-Commercial License (http://creativecommons.org/licenses/bync/4.0) which permits unrestricted non-commercial use, distribution, and reproduction in any medium, provided the original work is properly cited.

\section{ASSESSMENT OF COMPLEX CONGENITAL HEART DISEASE}

Cardiac CT can simultaneously provide information about the great vessels, cardiac chambers, and valve anomalies, with excellent spatial resolution and fast acquisition time in adult congenital heart disease [5].

Atrial septal defect (ASD) is the most common congenital heart disease. Among the four subtypes of ASD, ostium secundum ASD is the most common (70-80\%), followed by ostium primum ASD (15\%), sinus venosus ASD (10\%), and coronary sinus ASD $(<1 \%)$ [6]. Cardiac CT can help to evaluate ASD and its subtypes, measure a defect or rim size, and assess a combined anomaly. In most cases of ostium primum ASD, the anterior leaf of the mitral valve is cleft. Partial anomalous pulmonary venous return (PAPVR) is commonly associated with approximately $85 \%$ of sinus venosus and $10 \%$ to $15 \%$ of ostium secundum ASD cases (Fig. 1) [7].

Congenitally corrected transposition of the great arteries (ccTGA) is a rare congenital heart disease with atrioventricular and ventriculoarterial discordance. Ventriculoarterial discordance indicates that the morphological right ventricle connects to the aorta, and the morphological left ventricle connects to the pulmonary artery (Fig. 2). This double discordance results in physiologically corrected circulation, with the morphological left ventricle supplying the pulmonary circulation, and the 

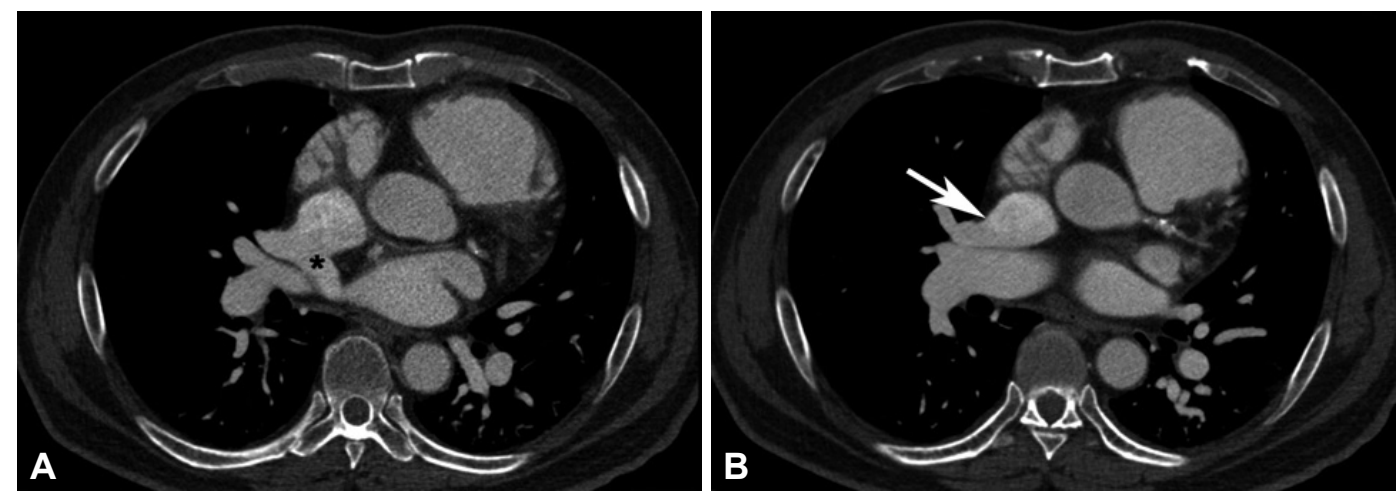

Fig. 1. Sinus venosus ASD with PAPVR. (A) Axial cardiac computed tomography image in a 53-year-old-male demonstrates a septal defect $\left(^{*}\right)$ between the left atrium and the superior vena cava-right atrial junction, consistent with sinus venosus ASD. (B) Axial image demonstrates a right superior pulmonary vein (arrow) draining into the superior vena cava, suggestive of PAPVR. ASD: atrial septal defect, PAPVR: partial anomalous pulmonary venous return.
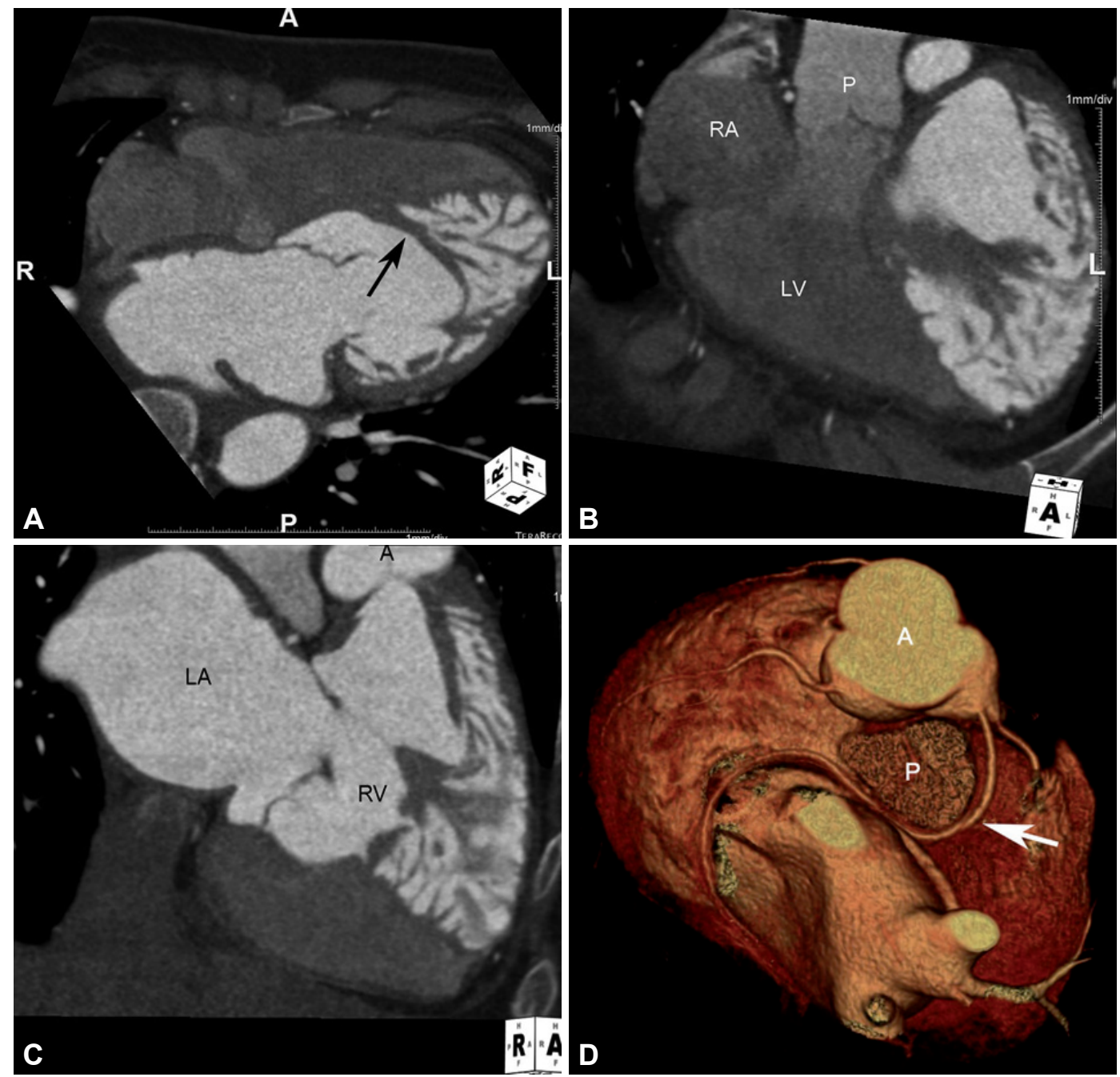

Fig. 2. Congenitally corrected transposition of the great arteries with coronary anomaly. (A) Four-chamber image from cardiac computed tomography in a 51-year-old female demonstrates the moderator band (arrow) with prominent trabeculation in the LV. (B) Three-chamber view of the RV demonstrates mitral-pulmonary fibrous continuity. (C) Three-chamber view of the LV demonstrates tricuspid-aortic fibrous discontinuity caused by the presence of a right ventricular infundibulum. (D) Volume-rendered image demonstrates combined coronary artery anomalies. In this patient, the right coronary artery arises from the right anterior sinus and travels along the left atrioventricular groove in a retropulmonary course (arrow). LA: left atrium, LV: left-sided ventricle, RA: right atrium, RV: right-sided ventricle, A: aorta, P: pulmonary trunk. 
morphological right ventricle supporting the systemic circulation [8]. Most patients with ccTGA have associated cardiac anomalies, including ventricular septal defect (70\%), pulmonary stenosis (40\%), and systemic atrioventricular valve (90\%), conduction (30\%), and coronary anomalies (45\%) [9-11].

Coarctation of the aorta $(\mathrm{CoA})$ is the fifth most common congenital heart disease, accounting for $6-8 \%$ of all cases [12]. It is characterized by narrowing of the aorta adjacent to the ductus arteriosus [13]. There are 3 types according to the narrowing site: 1) preductal (proximal to the ductus arteriosus), 2) ductal (at the level of the ductus arteriosus), and 3) postductal (distal to the ductus arteriosus). Postductal CoA is the most common type encountered in adults [14]. The most commonly associated anomaly is a bicuspid aortic valve, found in $75 \%$ of CoA patients (Fig. 3) [15,16]. Other associated anomalies include ventricular septal defect, sinus venosus ASD, hypoplastic left heart syndrome, mitral valve malformation, truncus arteriosus, right aortic arch, supravalvular pulmonary artery stenosis, and left subclavian artery dilatation [17]. Cardiac CT can provide anatomical details of the aorta and the narrowing segment as well as associated cardiovascular anomalies and collateral vessels for initial diagnosis [13].

Ebstein's anomaly is defined as displacement of the septal leaflet of the tricuspid valve into the right ventricle, with resultant atrialization of the basal part of the right ventricle (Fig. 4). Marked dilatation of the right heart generally reflects severe tricuspid regurgitation. It is an uncommon congenital heart disease, occurring in up to $1 \%$ of congenital heart disease patients [18]. Ebstein's anomaly can be associated with pulmonary stenosis or atresia, ventricular septal defect, mitral steno- sis, tetralogy of Fallot, and corrected or partial transposition of the great vessels [19]. Cardiac CT is regarded as a partial alternative to cardiac magnetic resonance. It can allow visualization of the position of the tricuspid valve, trabeculated myocardium, and combined cardiovascular anomalies if good opacification of the right ventricle is acquired with an appropriate con-

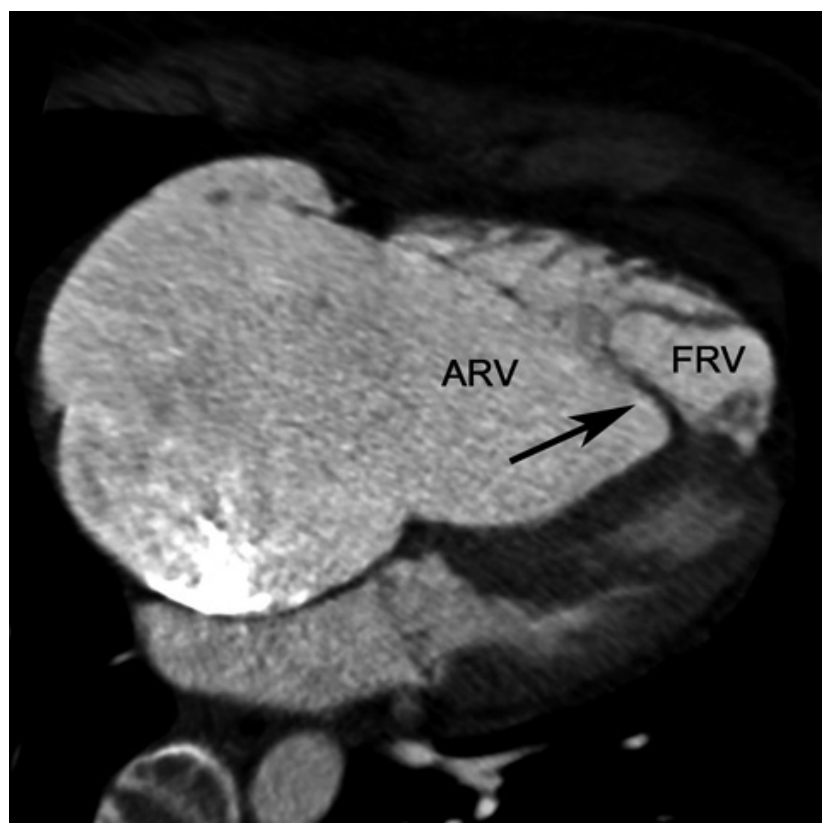

Fig. 4. Ebstein's anomaly. Four-chamber images from cardiac computed tomography in a 46-year-old female demonstrate dilation of the right ventricle and apical displacement of the septal and posterior leaflets of the tricuspid valve (arrow), compared with mitral septal leaflet insertion. Note the atrialized right ventricle (ARV) and functional right ventricle (FRV).
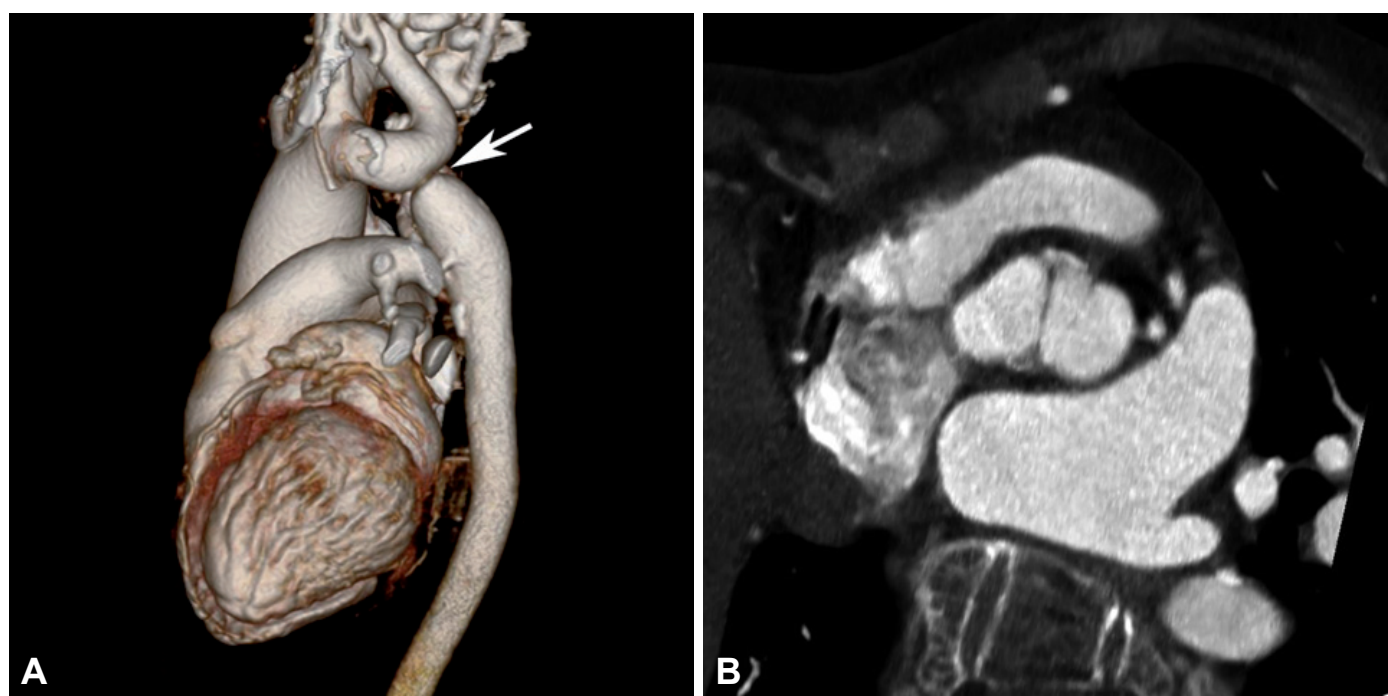

Fig. 3. Coarctation of the aorta with bicuspid aortic valve. (A) Volume-rendered image from cardiac CT in a 35-year-old female with Turner's syndrome demonstrates abrupt narrowing of the aorta (arrow) just distal to the left subclavian artery. (B) Cross-sectional CT reconstruction through the aortic valve plane in systole demonstrates an apparent single line of valve fusion, suggestive of bicuspid aortic valve. CT: computed tomography. 
trast material protocol, such as a triphasic protocol. Moreover, it is useful for both preoperative planning and postoperative follow-up, such as evaluation of the Fontan circuit.

Cor triatriatum is characterized by division of the left atrium (LA) or right atrium (RA) into two chambers by a fibromuscular membrane (Fig. 5). Although it usually involves the LA (cor triatriatum sinister), it can also involve the RA (cor triatriatum

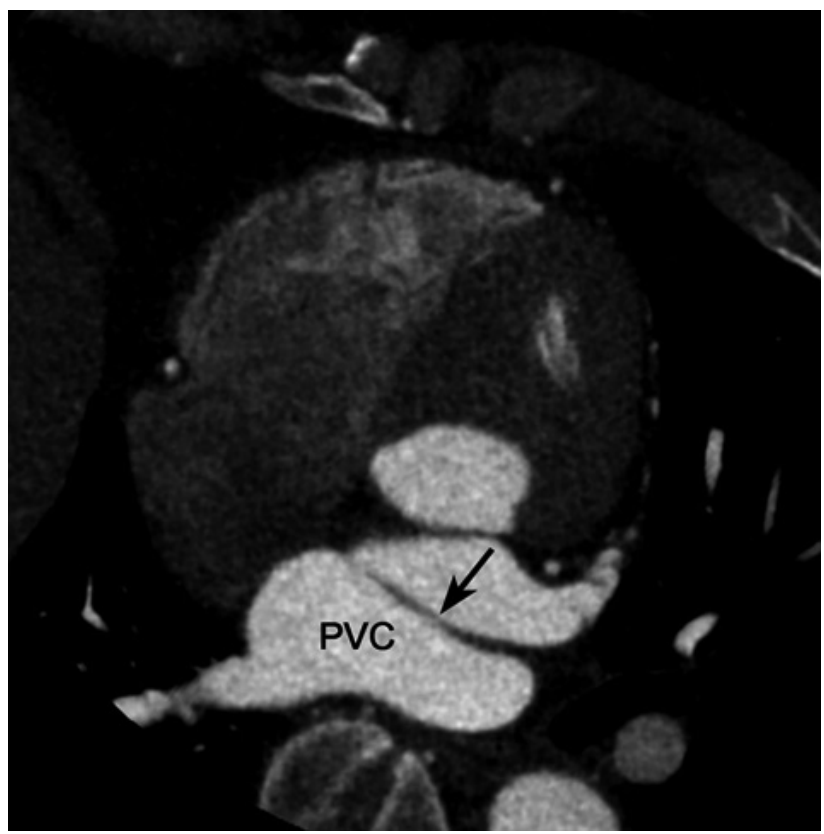

Fig. 5. Cor triatriatum. Oblique axial image from cardiac computed tomography in a 58-year-old male demonstrates a membrane (arrow) in the LA. This membrane separates the PVC of the LA from the main body of the LA. LA: left atrium, PVC: pulmonary venous compartment. dexter). The severity of clinical symptoms depends on the size of the fenestration in the fibromuscular membrane [20]. Other congenital cardiac anomalies such as ASD or anomalous pulmonary venous return can also be present [21].

\section{EVALUATION OF CARDIAC MASSES}

Cardiac masses are uncommon entities and can be categorized as either non-neoplastic or neoplastic. Non-neoplastic masses include thrombi and lipomatous hypertrophy of the interatrial septum [22]. Approximately 75\% of all primary tumors are benign, and the remaining $25 \%$ are primary malignant tumors. Primary benign tumors include myxomas ( $50 \%$ of all benign cardiac tumors), papillary fibroelastomas (20\%), lipomas (20\%), and hemangiomas (50\%). The most common type of malignant cardiac mass is metastasis, followed by sarcoma (95\% of all malignant primary cardiac tumors) and lymphoma (5\%). Noninvasive imaging modalities play an important role in the diagnosis and preoperative planning of cardiac masses [23]. Although echocardiography remains the preferred initial imaging modality for evaluation of cardiac masses, cardiac CT and magnetic resonance imaging (MRI) are often used synergistically with echocardiography. Cardiac CT is an alternative method for patients with inadequate images from other imaging modalities or with contraindications to MRI. Cardiac CT can help to characterize a calcified or fatty mass, detect metastasis, assess combined chest abnormalities, and exclude coronary artery disease [24]. To characterize a cardiac mass, low-dose non-contrast CT and delayed CT might be needed [22].

Thrombus is the most common type of intracardiac mass [23]. It is usually found in the left atrial appendage and is asso-
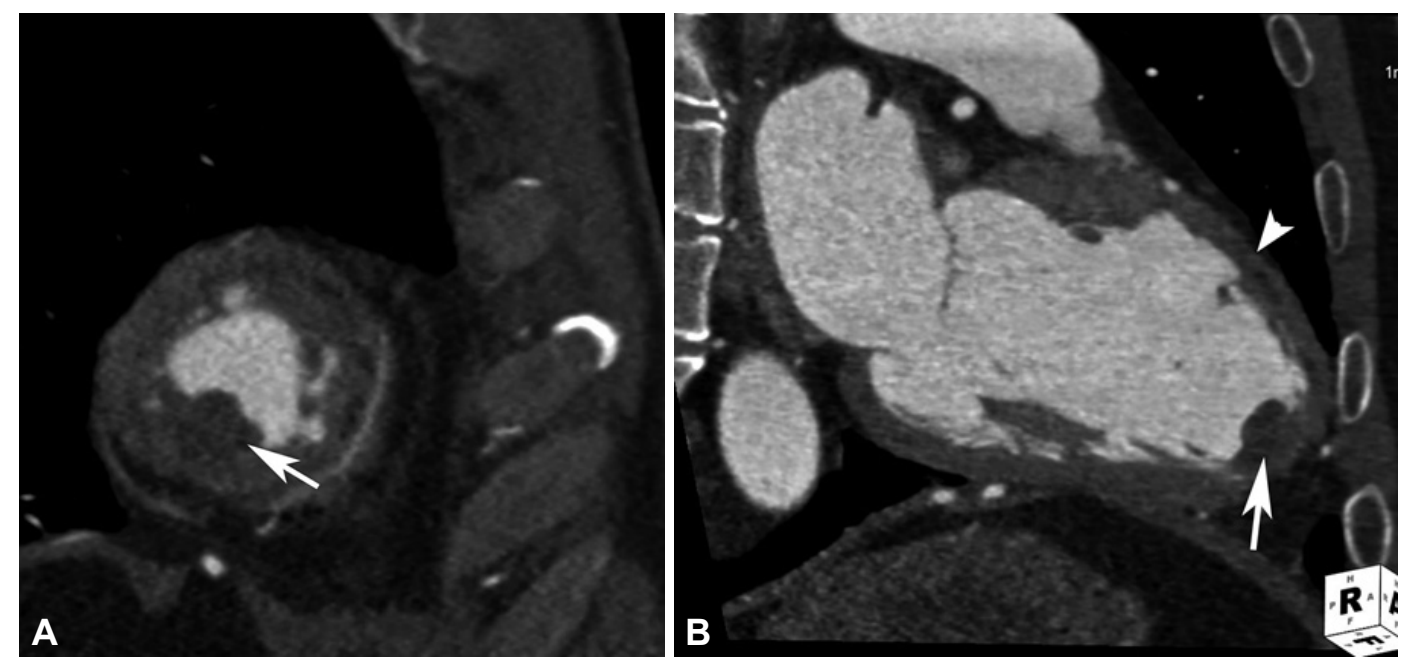

Fig. 6. Intracardiac thrombus. (A and B) Short-axis and 2-chamber images from cardiac computed tomography in a 51-year-old male demonstrate a hypodense filling defect consistent with thrombus (arrows) in the left ventricular apex. Note the myocardial thinning (arrowhead) due to prior infarction in the anterior wall of the left ventricle. The patient underwent percutaneous coronary intervention of the proximal to mid-left anterior descending coronary artery 6 years prior. 
ciated with a hypercoagulable state, atrial fibrillation, mitral valve disease, severe left ventricular dysfunction following myocardial infarction, or an artificial device. Differentiation between thrombus and tumor is essential because the treatment method is different. Knowledge of predisposing risk factors, shape, delayed enhancement, location, and lack of mobility can be useful when distinguishing thrombus from tumor [22]. The typical CT finding of a cardiac thrombus is a hypodense filling defect within a cardiac chamber (Fig. 6). Circulatory stasis, which describes incomplete mixing of blood and contrast media, can mimic thrombus in the left atrial appendage. In that situation, delayed CT imaging starting 30 seconds after the first scan can help to differentiate between thrombus and circulatory stasis [25].

A myxoma is commonly located in the LA attached to the fossa ovalis (60-75\%), followed by the RA (15-20\%), inferior vena cava, and the valve leaflets [26]. It usually has a smooth or lobular margin and heterogeneous enhancement, depending of chronicity and components (e.g., necrosis, hemorrhage). A mobile myxoma occasionally prolapses through the atrioventricular valves and causes obstruction (Fig. 7) [22].

A lipoma is a benign, encapsulated, mesenchymal tumor composed of mature adipose tissue and can be located at various sites. On CT, a lipoma is an encapsulated, fat-attenuating mass

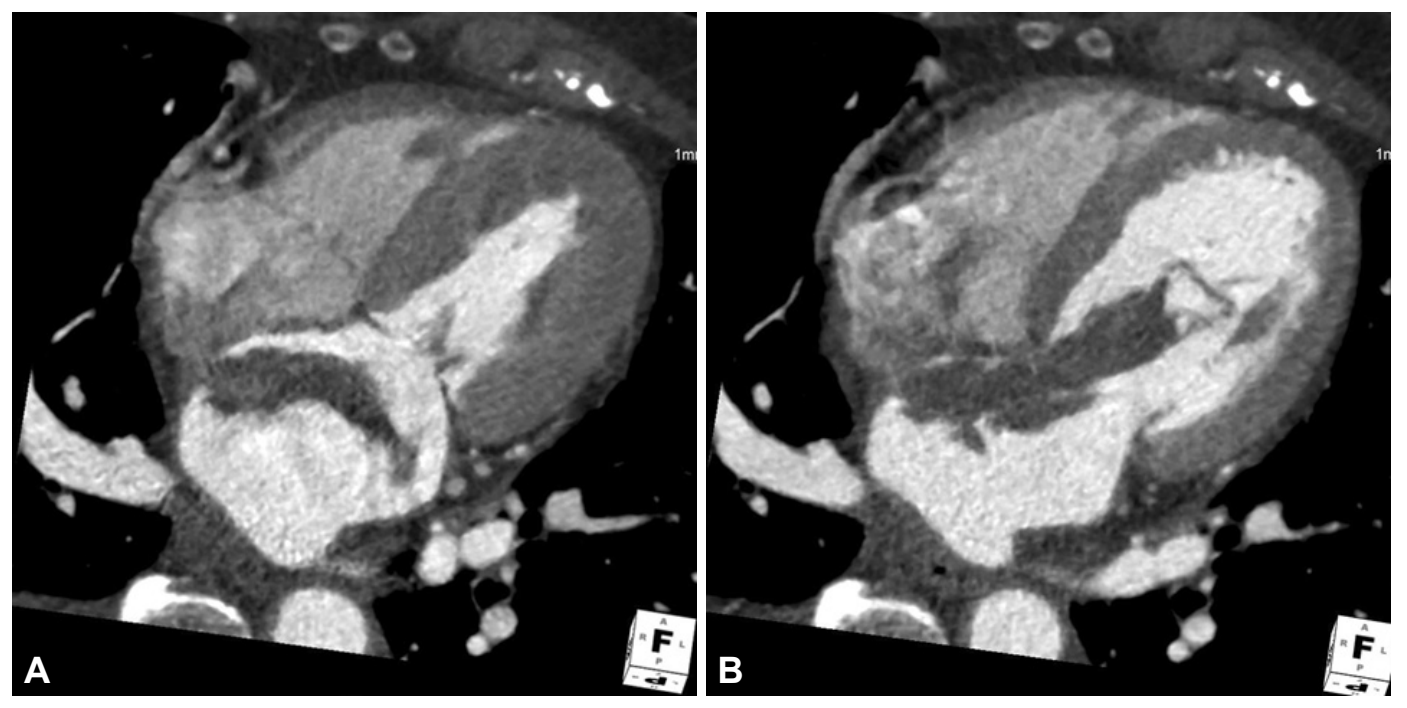

Fig. 7. Myxoma. (A) Four-chamber image from cardiac computed tomography in systole in a 70-year-old male demonstrates a large, low-attenuating mass with a small stalk attached to the fossa ovalis, consistent with myxoma. The mass has heterogeneous enhancement. (B) Fourchamber image in diastole shows a highly mobile mass prolapsing across the mitral valve and causing mitral valve obstruction.

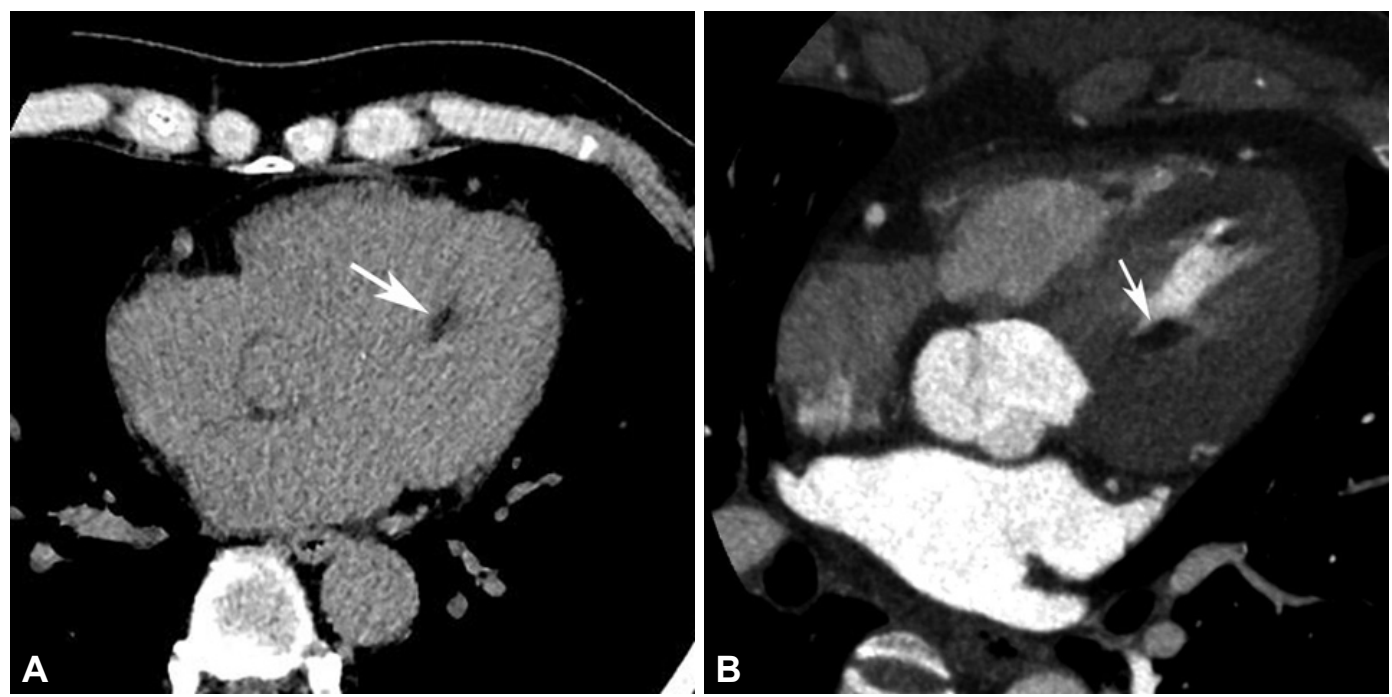

Fig. 8. Intracardiac lipoma. (A) Axial image from non-contrast CT for calcium scoring in a 56-year-old male demonstrates a low-attenuated, $-60-\mathrm{HU}$ mass (arrow) in the anterior papillary muscle. (B) Axial image from cardiac CT demonstrates no definite enhancement in the fatty mass (arrow). CT: computed tomography. 
without enhancement (Fig. 8). Multiple lipomas might be seen in tuberous sclerosis patients. Lipomatous hypertrophy of the interatrial septum, which is characterized by non-neoplastic accumulation of fat cells in the interatrial septum, can mimic lipoma because both are composed of fatty tissue. However, lipomatous hyperplasia of the interatrial septum is a nonencapsulated and non-neoplastic mass. It is associated with old age and obesity [27]. Characteristic CT findings include a dumbbell-shaped mass $(>2 \mathrm{~cm})$ arising from the interatrial septum, sparing of the fossa ovalis, and fat density $<-50 \mathrm{HU}$ (Fig. 9).

Sarcoma is the second most common primary cardiac tumor. Of all sarcomatous cell types, angiosarcoma is the most common. The majority $(80 \%)$ of angiosarcomas are located in the RA, although other types of sarcoma usually occur in the LA. CT findings of sarcoma show a broad-based mass with enhancement. Invasion to the myocardium, pericardium, mediastinum, or great vessels and extracardiac metastasis can be identified.

\section{EVALUATION OF PERICARDIAL CONDITION}

The pericardium is a double-layered fibroserous sac surrounding the heart and origin of the great vessels. It is composed of an inner serosa and outer fibrosa. Normal pericardium appears as a thin curvilinear structure on cardiac CT. Typically, the pericardium is best visualized along the right ventricle and is not visible over the lateral and posterior wall of the left ventricle. Pericardial thickness of $4 \mathrm{~mm}$ or more indicates abnormal thickening [28]. Cardiac CT allows for accurate assessment of pericardial anatomy and calcification without cardiac motion artifact. Moreover, using a larger field of view, mediastinal and chest abnormalities can be simultaneously examined. Using retrospective ECG-gated cardiac CT, evaluation of dynamic ventricular septal motion is possible [29].
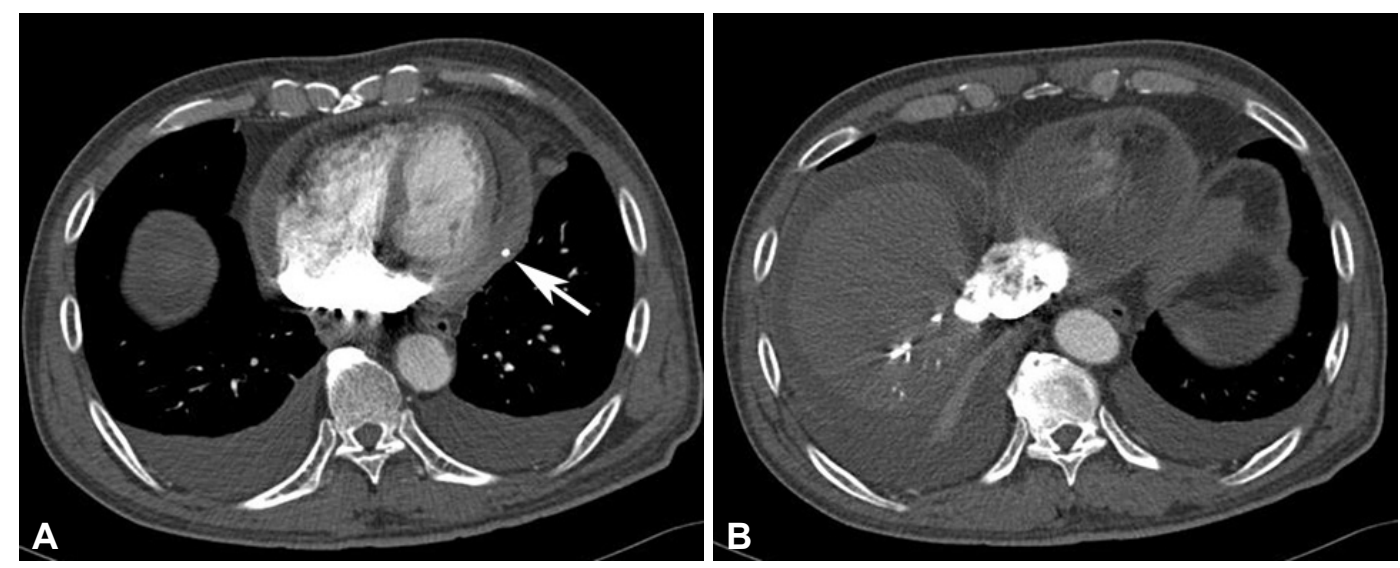

Fig. 10. Constrictive pericarditis. (A and B) Axial images from cardiac computed tomography in a 69-year-old male with dyspnea and facial edema demonstrate pericardial effusion with diffuse pericardial thickening and focal calcification (arrow). Ascites and dilatation of the inferior vena cava and hepatic vein are also noted. He underwent pericardiectomy.
Constrictive pericarditis is a condition in which the compliance of the pericardium is decreased, leading to restricted ventricular filling, severe diastolic dysfunction, and right heart failure. Causes of constrictive pericarditis include infection (particularly tuberculosis), mediastinal irradiation, and pericardiotomy. Diagnosis of constrictive pericarditis remains challenging and is based on imaging findings and functional and hemodynamic abnormalities. Typical CT findings of constrictive pericarditis include pericardial thickening with or without calcifications (Fig. 10). Constrictive pericarditis usually occurs in the

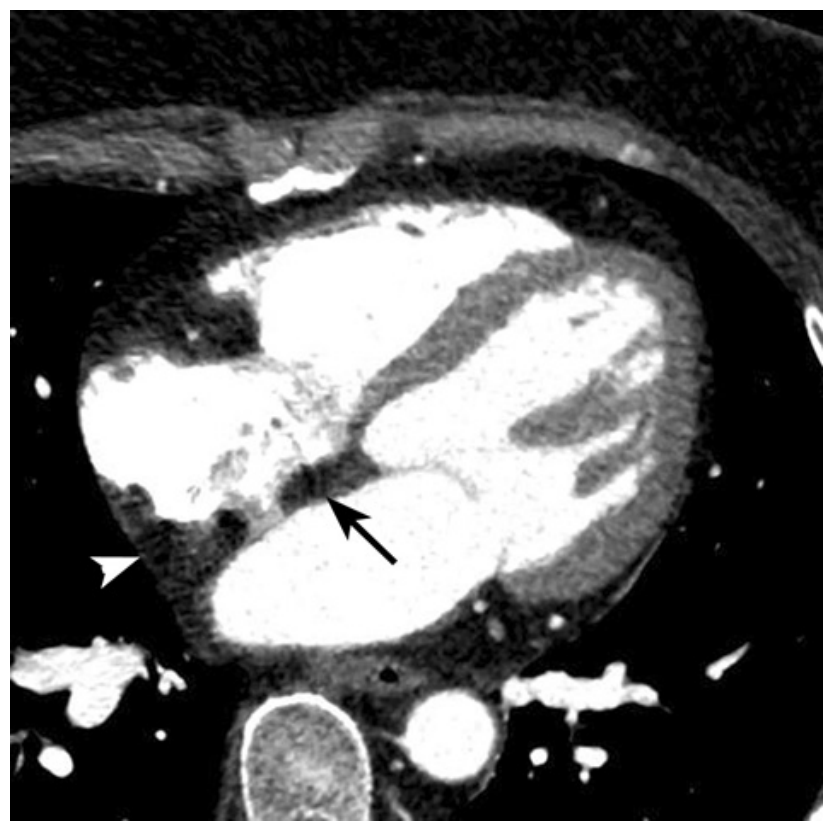

Fig. 9. Lipomatous hypertrophy of the interatrial septum. Axial image from cardiac computed tomography in a 38-year-old female demonstrates a mass (arrow) with fat-attenuation that spares the fossa ovalis, consistent with lipomatous hypertrophy of the interatrial septum. The mass extends to involve the posterior wall of the right atrium (arrowhead). 
right side of the heart or atrioventricular groove [28]. Reduced volume in the right ventricle with a narrow, tubular configuration, a sigmoid ventricular septum and prominent leftward septal convexity, systemic venous dilatation, hepatomegaly, and ascites can also be seen. However, neither pericardial thickening nor calcification is diagnostic of constrictive pericarditis, unless the patient also has symptoms of physiologic constriction or restriction [30].

A pericardial cyst results from pericardial tissue being pinched off during early development [30]. Typical CT findings of a pericardial cyst include a water-attenuated mass with a smooth wall and no enhancement, usually in the right cardiophrenic angle (Fig. 11). When a pericardial cyst has variable attenuation, highly proteinaceous fluid or hemorrhage in the cyst should be suspected. A pericardial cyst can occur anywhere in the mediastinum and can mimic a bronchogenic or thymic cyst.

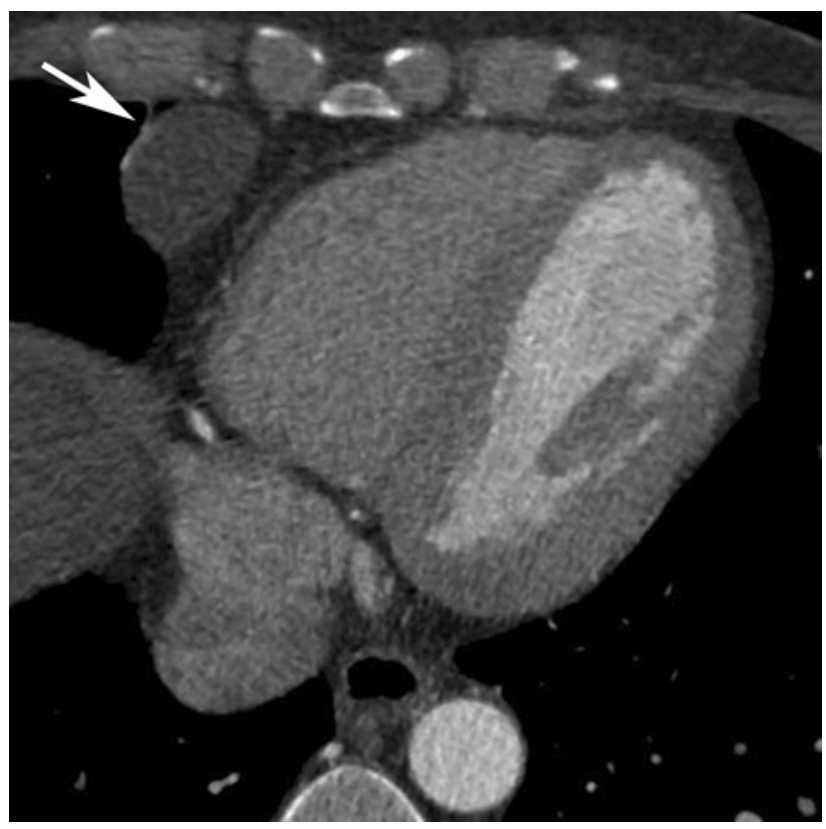

Fig. 11. Pericardial cyst. Axial image from cardiac computed tomography in a 40-year-old male demonstrates a cystic mass at the right cardiophrenic angle, consistent with a pericardial cyst (arrow).
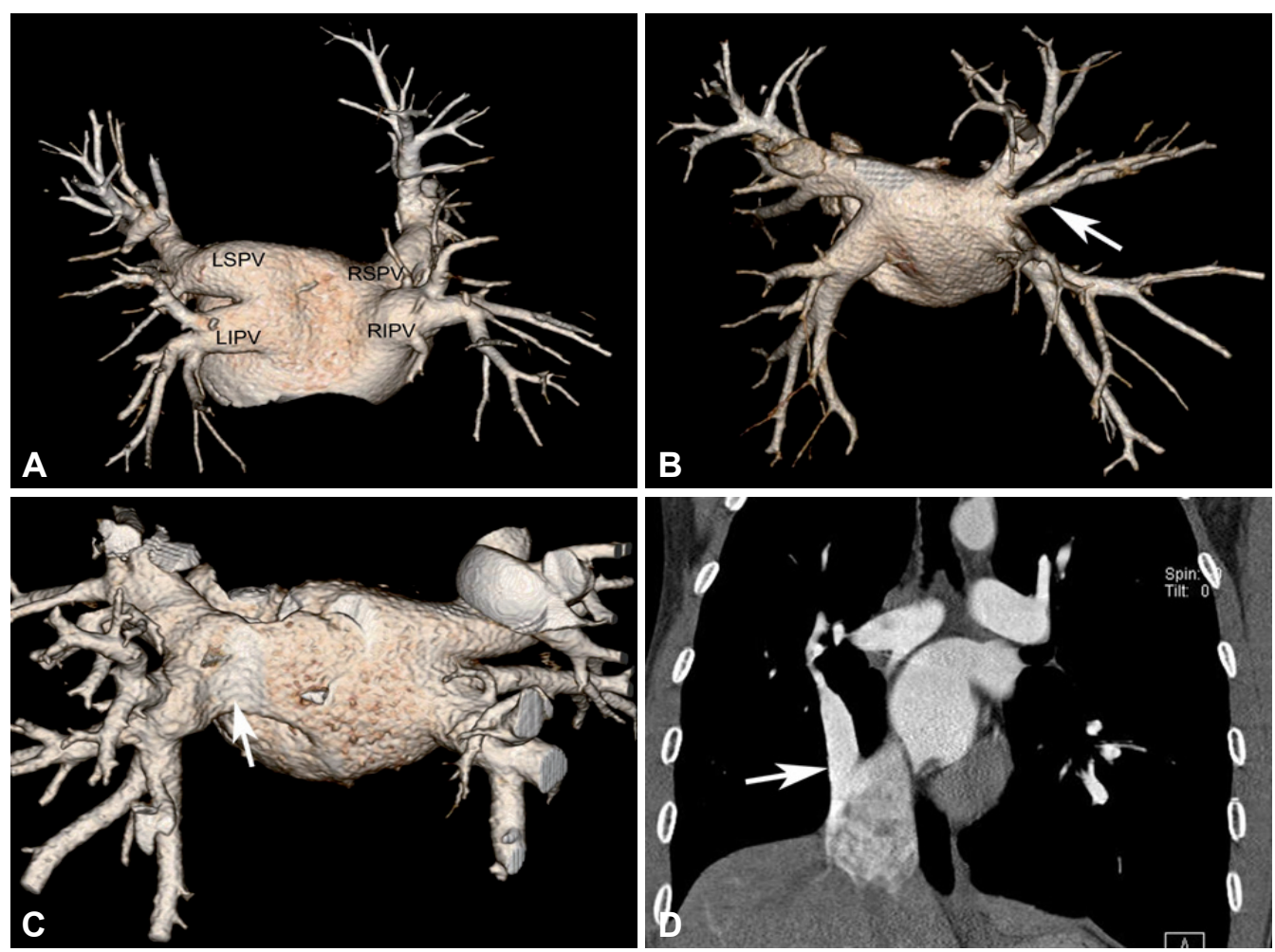

Fig. 12. Normal pulmonary vein and common pulmonary vein variant. (A) Normal pulmonary vein. Three-dimensional volume-rendering images of the LA and pulmonary veins were routinely constructed for each patient prior to radiofrequency ablation. This image in a $27-y e a r-$ old male with atrial fibrillation demonstrates a normal pulmonary vein. The RSPV, RIPV, LSPV, and LIPV drain into the LA. (B) Separate right middle lobe pulmonary veins. Three-dimensional volume-rendering image in a 65-year-old male with atrial fibrillation demonstrates separate drainage of the RMPV (arrow) into the LA. (C) Joint pulmonary vein. Three-dimensional volume-rendering image in a 40-year-old female with a joint pulmonary vein demonstrates a common left trunk (arrow). (D) Anomalous pulmonary venous return. Coronal reformatted computed tomography image in a 20-year-old man with partial anomalous pulmonary venous return demonstrates the right superior and inferior pulmonary vein (arrow) draining into the inferior vena cava. LA: left atrium, RSPV: right superior pulmonary vein, RIPV: right inferior pulmonary vein, LSPV: left superior pulmonary vein, LIPV: left inferior pulmonary vein, RMPV: right middle pulmonary vein. 


\section{EVALUATION OF PULMONARY VEIN ANATOMY PRIOR TO RFA FOR ATRIAL FIBRILLATION}

RFA with electro-isolation of the pulmonary veins is a therapeutic strategy increasingly used to treat refractory atrial fibrillation [31]. Cardiac CT has been used to assess the pulmonary venous anatomy and presence of left atrial thrombus prior to RFA [32]. Preprocedural cardiac CT can provide specific information regarding the pulmonary vein and LA prior to RFA as follows: 1) number and location of pulmonary veins and pulmonary venous anomalies; 2 ) ostial diameter of individual pulmonary veins; 3 ) left atrial dimensions; 4) identification of left atrial appendage thrombus; 5) anatomy of the esophagus to minimize complications such as atrioesophageal fistula; and 6) co-registration with electroanatomic mapping prior to RFA or direct overlay onto live fluoroscopic images in the electrophysiology laboratory [33].

Normally, there are two superior and two inferior pulmonary veins (Fig. 12A). The left superior pulmonary vein drains the left upper lobe, and the right superior pulmonary veins drain the right upper and middle lobes. The inferior pulmonary veins drain their respective lower lobes. Common anomalies include separate right middle lobe pulmonary veins (19-23\%), joint pulmonary veins (superior and inferior common trunk, 2.4$25 \%$ ), and anomalous pulmonary venous return $(<1 \%)$ (Fig. 12B, C, and D) [32].

\section{NONINVASIVE CORONARY VEIN MAPPING PRIOR TO PLACEMENT OF BIVENTRICULAR PACEMAKER}

In end-stage heart failure, cardiac resynchronization therapy (CRT, biventricular pacing) has been increasingly used for increased survival and symptomatic relief. In this method, an additional left ventricular lead is placed in the target coronary vein on the surface of the left ventricle, together with the classic pacing of the right ventricle and the RA. The left ventricular lead is implanted through cannulation of the coronary sinus and the great cardiac vein to the lateral or posterolateral veins, which are considered the target veins. A major problem is the significant anatomical variability of the coronary venous system. Therefore, cardiac CT is usually used to assess the coronary venous anatomy for guidance of left ventricular lead placement. The diameters of the coronary sinus and target veins can be measured. Cardiac CT also can be used to evaluate left ventricular ejection fraction and the burden and location of myocardial scarring prior to CRT [33]. The CT technique is similar to that for routine coronary $\mathrm{CT}$ angiography. However, for optimal visualization of the coronary vein, an additional delay of 4 seconds com- pared to that used for coronary CT angiography is appropriate [34].

\section{CONCLUSIONS}

Cardiac CT is a powerful imaging tool for detection of both non-coronary cardiovascular disease and coronary artery disease. We reviewed the cardiac CT findings of non-coronary disease in adults. Radiologists should be aware of these applications and imaging findings in adult cardiac CT.

\section{Conflicts of Interest}

The authors declare that they have no conflict of interest.

\section{Acknowledgments}

This work was supported by the 2017 Clinical Research Grant from Pusan National University Hospital.

\section{REFERENCES}

1. Raff GL, Gallagher MJ, O’Neill WW, Goldstein JA. Diagnostic accuracy of noninvasive coronary angiography using 64-slice spiral computed tomography. J Am Coll Cardiol 2005;46:552-557.

2. Abdulla J, Abildstrom SZ, Gotzsche O, Christensen E, Kober L, TorpPedersen C. 64-multislice detector computed tomography coronary angiography as potential alternative to conventional coronary angiography: a systematic review and meta-analysis. Eur Heart J 2007;28:3042-3050.

3. Budoff MJ, Dowe D, Jollis JG, Gitter M, Sutherland J, Halamert E, et al. Diagnostic performance of 64-multidetector row coronary computed tomographic angiography for evaluation of coronary artery stenosis in individuals without known coronary artery disease: results from the prospective multicenter ACCURACY (Assessment by Coronary Computed Tomographic Angiography of Individuals Undergoing Invasive Coronary Angiography) trial. J Am Coll Cardiol 2008;52:1724-1732.

4. Hendel RC, Patel MR, Kramer CM, Poon M, Hendel RC, Carr JC, et al. ACCF/ACR/SCCT/SCMR/ASNC/NASCI/SCAI/SIR 2006 appropriateness criteria for cardiac computed tomography and cardiac magnetic resonance imaging: a report of the American College of Cardiology Foundation Quality Strategic Directions Committee Appropriateness Criteria Working Group, American College of Radiology, Society of Cardiovascular Computed Tomography, Society for Cardiovascular Magnetic Resonance, American Society of Nuclear Cardiology, North American Society for Cardiac Imaging, Society for Cardiovascular Angiography and Interventions, and Society of Interventional Radiology. J Am Coll Cardiol 2006; 48:1475-1497.

5. Orwat S, Diller GP, Baumgartner H. Imaging of congenital heart disease in adults: choice of modalities. Eur Heart J Cardiovasc Imaging 2014;15: 6-17.

6. Warnes CA, Williams RG, Bashore TM, Child JS, Connolly HM, Dearani JA, et al. ACC/AHA 2008 guidelines for the management of adults with congenital heart disease: a report of the American College of Cardiology/ American Heart Association Task Force on Practice Guidelines (Writing Committee to Develop Guidelines on the Management of Adults With Congenital Heart Disease). Developed in Collaboration With the American Society of Echocardiography, Heart Rhythm Society, International Society for Adult Congenital Heart Disease, Society for Cardiovascular Angiography and Interventions, and Society of Thoracic Surgeons. J Am Coll Cardiol 2008;52:e143-e263.

7. Sahay S, Krasuski RA, Tonelli AR. Partial anomalous pulmonary venous connection and pulmonary arterial hypertension. Respirology 2012;17: 957-963.

8. Wallis GA, Debich-Spicer D, Anderson RH. Congenitally corrected trans- 
position. Orphanet J Rare Dis 2011;6:22.

9. Warnes CA. Transposition of the great arteries. Circulation 2006;114: 2699-2709.

10. Friedberg DZ, Nadas AS. Clinical profile of patients with congenital corrected transposition of the great arteries. A study of 60 cases. N Engl J Med 1970;282:1053-1059.

11. Ismat FA, Baldwin HS, Karl TR, Weinberg PM. Coronary anatomy in congenitally corrected transposition of the great arteries. Int J Cardiol 2002;86:207-216.

12. Kenny D, Hijazi ZM. Coarctation of the aorta: from fetal life to adulthood. Cardiol J 2011;18:487-495.

13. Karaosmanoglu AD, Khawaja RD, Onur MR, Kalra MK. CT and MRI of aortic coarctation: pre- and postsurgical findings. AJR Am J Roentgenol 2015;204:W224-W233.

14. Thakkar AN, Chinnadurai P, Lin CH. Imaging adult patients with coarctation of the aorta. Curr Opin Cardiol 2017;32:503-512.

15. Smith DE, Matthews MB. Aortic valvular stenosis with coarctation of the aorta, with special reference to the development of aortic stenosis upon congenital bicuspid valves. Br Heart J 1955;17:198-206.

16. Becker AE, Becker MJ, Edwards JE. Anomalies associated with coarctation of aorta: particular reference to infancy. Circulation 1970;41:1067-1075.

17. Kimura-Hayama ET, Meléndez G, Mendizábal AL, Meave-González A, Zambrana GF, Corona-Villalobos CP. Uncommon congenital and acquired aortic diseases: role of multidetector CT angiography. Radiographics 2010;30:79-98.

18. Link KM, Herrera MA, D’Souza VJ, Formanek AG. MR imaging of Ebstein anomaly: results in four cases. AJR Am J Roentgenol 1988;150:363367.

19. Lev M, Liberthson RR, Joseph RH, Seten CE, Eckner FA, Kunske RD, et al. The pathologic anatomy of Ebstein's disease. Arch Pathol 1970;90:334343.

20. Öztürk E, Kafadar C, Tutar S, Bozlar U, Hagspiel KD. Non-coronary abnormalities of the left heart: CT angiography findings. Anatol J Cardiol 2016;16:720-727.

21. Humpl T, Reineker K, Manlhiot C, Dipchand AI, Coles JG, McCrindle BW. Cor triatriatum sinistrum in childhood. A single institution's experience. Can J Cardiol 2010;26:371-376.

22. Kassop D, Donovan MS, Cheezum MK, Nguyen BT, Gambill NB, Blankstein R, et al. Cardiac masses on cardiac CT: a review. Curr Cardiovasc Imaging Rep 2014;7:9281.

23. Motwani M, Kidambi A, Herzog BA, Uddin A, Greenwood JP, Plein S. MR imaging of cardiac tumors and masses: a review of methods and clinical applications. Radiology 2013;268:26-43

24. Klein AL, Abbara S, Agler DA, Appleton CP, Asher CR, Hoit B, et al. American Society of Echocardiography clinical recommendations for multimodality cardiovascular imaging of patients with pericardial disease: endorsed by the Society for Cardiovascular Magnetic Resonance and Society of Cardiovascular Computed Tomography. J Am Soc Echocardiogr 2013;26:965-1012.e15.

25. Hur J, Kim YJ, Lee HJ, Ha JW, Heo JH, Choi EY, et al. Left atrial appendage thrombi in stroke patients: detection with two-phase cardiac CT angiography versus transesophageal echocardiography. Radiology 2009;251: 683-690.

26. Grebenc ML, Rosado-de-Christenson ML, Green CE, Burke AP, Galvin JR. Cardiac myxoma: imaging features in 83 patients. Radiographics 2002; 22:673-689.

27. Heyer CM, Kagel T, Lemburg SP, Bauer TT, Nicolas V. Lipomatous hypertrophy of the interatrial septum: a prospective study of incidence, imaging findings, and clinical symptoms. Chest 2003;124:2068-2073.

28. Bogaert J, Francone M. Pericardial disease: value of CT and MR imaging. Radiology 2013;267:340-356.

29. Ghersin E, Lessick J, Litmanovich D, Ofer A, Elhasid R, Lorber A, et al. Septal bounce in constrictive pericarditis. Diagnosis and dynamic evaluation with multidetector CT. J Comput Assist Tomogr 2004;28:676-678.

30. Wang ZJ, Reddy GP, Gotway MB, Yeh BM, Hetts SW, Higgins CB. CT and MR imaging of pericardial disease. Radiographics 2003;23 Spec No:S167S180.

31. Fuster V, Rydén LE, Cannom DS, Crijns HJ, Curtis AB, Ellenbogen KA, et al. $2011 \mathrm{ACCF} / \mathrm{AHA} / \mathrm{HRS}$ focused updates incorporated into the ACC/ AHA/ESC 2006 Guidelines for the management of patients with atrial fibrillation: a report of the American College of Cardiology Foundation/ American Heart Association Task Force on Practice Guidelines developed in partnership with the European Society of Cardiology and in collaboration with the European Heart Rhythm Association and the Heart Rhythm Society. J Am Coll Cardiol 2011;57:e101-e198.

32. Cronin P, Sneider MB, Kazerooni EA, Kelly AM, Scharf C, Oral H, et al. $\mathrm{MDCT}$ of the left atrium and pulmonary veins in planning radiofrequency ablation for atrial fibrillation: a how-to guide. AJR Am J Roentgenol 2004;183:767-778.

33. Thai WE, Wai B, Truong QA. Preprocedural imaging for patients with atrial fibrillation and heart failure. Curr Cardiol Rep 2012;14:584-592.

34. Shah SS, Teague SD, Lu JC, Dorfman AL, Kazerooni EA, Agarwal PP. Imaging of the coronary sinus: normal anatomy and congenital abnormalities. Radiographics 2012;32:991-1008. 